\title{
THE ROLE OF FINANCIAL INSTRUMENTS ON THE GROWTH OF ITALIAN SOCIAL COOPERATIVES
}

\author{
${ }^{1}$ Francesco Agliata, ${ }^{2}$ Caterina Ferrone and ${ }^{1}$ Danilo Tuccillo \\ ${ }^{1}$ Department of Economics, Second University of Naples, Italy \\ ${ }^{2}$ Department of Economics, Management, Institutions, University of Naples "Federico II", Italy
}

Received 2014-03-16; Revised 2014-04-24; Accepted 2014-05-05

\begin{abstract}
The Third Sector in Italy records a slow but constant growth due to the increase of the number of entities but not of their dimension. The difficulties in financial management, generated by a low attraction of debt and equity financial resources and a low level of managerial skills characterized the non profit organizations. Focused on the social cooperatives, the article describe the effects on the financial structure of innovative financial instruments as the participative loan. In the last years in Italy there has been an increasing attention towards the ethical finance. The consideration of the social co-ops as a part of the Third Sector allows them to have a privileged interlocution with the institutions of the ethical finance. But the development of this institutions, although it is originated from the will to support the social responsible development, at the moment seems not to support a substantial resolution of the financial needs related to the management of the social cooperatives. The article shows an analysis on a particular financial intermediary, the Cooperazione Finanza Impresa (CFI). This institution is a private equity investor which since twenty years is dedicated to worker cooperatives and social cooperatives. The interest for this institution, besides the entities financed, is based on a particular form of participative loan developed. The investigation start from the observation of a singular social cooperatives with the elaboration of a set of indicators based on the financial ratio analysis. The evaluation regard the financial structure previous to the financing operation and its subsequent modification. Due to the first conclusions, the investigation enlarged the analysis to a sample of 10 social cooperatives in order to confirm the first results. The observation of modified financial structure up a period of five years shows significative positive change that support both the economic and the financial equilibrium, with a significant reduction of the average cost of the debt in all the cooperatives financing by participative loans.
\end{abstract}

Keywords: Social Cooperatives, Financial Instruments, Performance Analysis

\section{INTRODUCTION}

The recent development of the non profit organizations in Italy has been followed by a slow but constant increase which may be due to various factors amongst which there are:

- A set of fragmentary rules not always so clear and useful for the third sector

- A low level of managerial attitude in non profit organizations
- The difficulties in financial management, generated by a low attraction of debt and equity financial resources

The aim of our research is to analyze the problems of the financial management in social cooperatives, investigating:

- The characteristics of financial needs and the financial instruments currently available, also in light of the innovations introduced by the social reform of 2003

Corresponding Author: Francesco Agliata, Department of Economics, Second University of Naples, Italy 
- The modifications to the financial structure operated by the choice of various instruments, through the analysis of a business specific case

The methodology in use follows the typical inductive-deductive approach of the Italian and Central European business economics studies. The first step is to define the research object; secondly to develop, within a descriptive-inductive dimension, an analysis on a group of social co-ops financed with a specific financial instruments, in order to verify the effects of this choice on the financial structure.

After a short description of the Non profit-sector in Italy (section 1) and of its various actors, the study focused on the social cooperatives (section 2); these institutions have been regulated by the Italian law with the enactment of the act n. 381 of 1991. This act should be considered as a result of a "legal and constitutional acknowledgment" of the activity of some cooperatives as organizations of public interest.

The choice of the research object is motivated by the acknowledgment that, in the context of the Italian non profit organizations, the social cooperatives represent the most articulated and advanced example of a "social enterprise". The social cooperatives have their own characteristics and their own financial needs and these are different from those of the profit organizations.

In accordance with the European law, recently companies rules have extended to the cooperatives the possibility to issue new financial instruments, with the aim to facilitate their capitalization.

Our research, in the light of this recently legislative reform, intends to analyze the effects of the application of innovative financial instruments on the social cooperatives financial structure. The observation is conducted on a five years period.

\subsection{Third Sector in Italy}

The development of Third sector in Italy (ISTAT, 2003; 2014) began in the middle of the Seventies, when the birth of new organizational systems were promoted by the civil society, especially the voluntary and community organizations.

The arise of new social needs in the community, in sanitary services, education, ecc., has stimulated the answer by people of such "common interests", exceeding the logic of an exclusive relationship between State and Citizens and constituting private organizations operating in the field of social care (Defourny, 2001; Desrochers and Fischer, 2005; Evers and Laville, 2004).
Today the Third sector includes many organizations, with different structures of partnership, but all the subjects are non profit organizations (Weisbrod, 1975; Airoldi, 1996; Capaldo, 1996; Matacena, 1999) which operate without objective of profit for their own purpose of social usefulness or solidarity scopes.

In Italy an organic normative does not exist for the third sector but Italian law disciplines, with different acts:

- Not governmental organizations (L. 49/1987)

- The voluntary service organizations (L. 266/1991)

- Social cooperatives (L. 381/1991)

- Banking former foundations (L. 461/1998)

- The associations of social promotion (L. 383/2000)

- The charities and public attendance institutions (L. 6972/1890 modified with L. 328/2000)

- Patronages (L. 152/2001)

- Committees and not banking private foundations (disciplined from the Civil code)

The absence of an organic body of rules in the non profit sector is a singular case in Europe. The Italian legislator has tried to make laws in matter but has not succeeded in the attempt.

Also in doctrinal position it seems difficult to find an opinion on the topic.

In an international search they have defined the elements that "characterize" an organization like pertaining to the non profit sector (Weisbrod, 1975; Airoldi, 1996; Capaldo, 1996; Matacena, 1999), as based on:

- Absence of distribution of the profits

- Private legal nature

- Formal constitution of the organization

- Self-government (not to be controlled from external subjects)

- Presence of voluntary job

- Democratise of the organization (election of the charges and effective participation of the supporters)

The census of the ISTAT published in 2003 about the organizations profit give evidence that the number is increased from 61.376 in 1991 to 235.232 in 2001. For the voluntary service organizations the only recorded increase is the one realized between 2001 and 2003, which was of $14.9 \%$. However, the increase in Third Sector-can be ascribed to the constitution of new organizations and not to the growth of those pre-existing.

According to the last survey of the ISTAT (2003), the field of the cooperation marks in Italy an increase anniversary of more than $11 \%$, records 225 thousands amongst stable and voluntary occupied working units; the value of the production from the social cooperation 
piles to 4,5 billions of euro, with average of 720.000 euro for every cooperative.

\subsection{The Social Cooperatives in Italy}

A blend of old and new features, using volunteers and what would be considered less desirable workers, the Italian social cooperatives are deserving of notice. These cooperatives developed to furnish welfare services to the "economically weaker layers of society" as Italy (Matacena, 1990; Travaglini, 1997; Lionzo, 2002), like other western European nations which had developed extensive welfare state programs, sought to diminish the financial burden of such programs. The first experiments with this new entrepreneurial form began in Italy in the late 1970's. Major growth followed the enactment of a law on social cooperatives. But that law, first drafted in 1981, was ten years in the making, as political parties and Italy's major cooperative groups debated its exact form. The law was passed late in 1991, with act. n. 381 "Discipline of the social cooperatives".

At the end of the Seventies it began to be perceived that new type of cooperation was being developed, which needed the definition of its legal characteristics.

It then began a debate about these new forms of cooperatives, characterized by solidarity. This happened in an historical context in which they were speaking a lot about welfare and non profit.

The long procedure for the emanation of a specific law, finds explanation in the fact that, it had to discipline a developed economic phenomenon in an independent way.

Inside about the movement of the social cooperation it is spoken about social cooperatives in terms of solidarity cooperatives.

We indicate in synthesis the main points of the law that has disciplined the phenomenon of the cooperatives of social solidarity, then defined social cooperatives:

- Definition of the social scope "has the scope to pursue the general interest of the community"

- In order to achieve this scope two possible activities are indicated that it can carry out the social cooperative

- The management of services associate-sanitary and educated to you

- The development of whichever economic activity having like purpose the working insertion of disadvantaged people

Classifying, based on the typologies of activity chosen between those indicated, the social cooperatives of type A to manage associate-sanitary services and educated and the social cooperatives to you of type B they carry out activity of working insertion of subjects disadvantaged, through whichever economic activity:

- For before the time one gives the possibility to the volunteers to become associates of the cooperative, not Exceeding but the half of the total number of the associates

- The category of disadvantaged peoples is defined

- Ulterior economic restrictions are not demanded, in order to the distribution of profits, reservoirs or through Drawbacks, if not for indicated how much for the ordinary cooperatives

- He possibility is previewed, for the social cooperatives enrolled in the regional dawn that carries out activity for the Working insertion, to stipulate conventions with Public Administration

- Some fiscal facilities for the particular nature of the carried out activity are applied to the social cooperatives, as an Example are considered of the agencies "of right" for being able to benefit of the regimen of facility in quality of Not Profit Organizations for general benefit of the communityONLUS in Italian acronym

- The constitution of social consortia is previewed, with the obligation that at least $70 \%$ of the social base are formed from social cooperatives

At last the law imposed to the Regions to emanate the implementing norms in matter of:

- White institution of the regional one of the social cooperatives

- Conventions specimen to stipulate with Public Administration

From what has been synthetically underlined, it is evident that the purpose indicated for the social cooperative by the legislator "the social cooperatives have the aim to pursue the general interest of the community" represents a critical point of the cooperation model.

The model of the social cooperation becomes, through the prescription of the legislator, a hybrid model (Fici, 2005). In fact to the social cooperative the registration is demanded in:

- Registry of prefecture in the field of activity in which work

- Registry of prefecture for the social cooperatives

The associates in the social cooperatives. The discipline of the cooperatives previews the existence of two categories of partner associates: The ordinary members and the financial backer partner. 
The members are those who are interested to the mutuality relationship that establishes with the cooperative in order to the obtaining of a good or a service to an inferior price regarding that one of market or other benefit.

The members have limitations regards:

- The remuneration of the equity

- Prohibition of distribution of the reserves during the life of the society

- The devolution, at the dissolution of the cooperative, of the resources which exceed equity capital to other mutuality, in order to promote the development of the cooperation

The financing member is who buys the financial instruments that confer the participation to the cooperative in order to carry out an investment.

They have limited rights as regards the entrepreneurial management of the cooperative, such as:

- They cannot receive more than one third of the voting rights attributable to the members present in the assembly

- They cannot appoint more than a third party of the administrators

- They cannot appoint more than a third of the members of the supervisory board

In the social cooperatives we can outline three categories of members:

- Ordinary members

- Voluntary members

- Financing members

The ordinary members carry out an activity for which they receive a remuneration and they are also equalled to the employees as regards the social security service.

Inside this category, in the social cooperatives, we distinguish:

- The ordinary members

- The disadvantaged members

The disadvantaged members are present in the social cooperatives of type $B$, because this type of cooperative is born with the scope to develop an economic activity in order to integrate disadvantaged people into the labour market.

Moreover the discipline of the cooperatives of type B previews:

- The possibility for such cooperative to carry out entrepreneurial activity without few limitation of the activity field

- The presence in the company of disadvantaged workers which must represent at least $30 \%$ of members
- A possible facility for the activity carried out by the cooperative through:

- The stipulation of conventions with Public Administration, becoming therefore a privileged interlocutor of the State and not having necessarily to operate in a competitive market

- The stipulation of conventions with Public Administration, becoming therefore a privileged interlocutor of the State and not having necessarily to operate in a competitive market

Recently it has been previewed the emanation of internal regulations for the discipline of the relationship between members and worker.

The voluntary member is a member which give their working activity for solidarity scope.

The figure of the voluntary member must be previewed in the statute of the cooperative. Those one have the right to the reimbursement of "expenses effectively supported" in the exercise of its activity is recognized.

The financing members are legal entities or individual investors who bring money to the cooperative with aim of investment, in order to obtain financial proceeds.

The financing members constitute a special category of members which have financial instruments; those ones may be transferred according to particular conditions than clause of pre-emption and pleasure are not previewed in the statute.

The society reform (Forestieri, 2002) previews the possibility to distinguish three various kinds of cooperatives:

- Cooperatives to prevailing mutuality

- Cooperatives to not prevailing mutuality

- Cooperatives to external mutuality

The cooperatives of prevailing mutuality have economic exchanges in prevalence with their own members; for the social cooperatives, the mutuality is recognized directly by the law, according to the characteristics of its own activities, because its objective is the general benefit of the community and the social integration of citizens.

Within the cooperatives of prevailing mutuality there are 14 various categories of cooperatives. The three more numerous categories are in the order:

- Worker Cooperatives (20,448 registrations)

- Building cooperatives

- Social cooperatives $(9,617$ registrations)

To carify the classification of the numerosity of the categories of cooperatives to prevailing mutuality, see the Table 1. 
Table 1. Classification of the numerosity of the categories of cooperatives to prevailing mutuality (absolute Values and percentages; January 2006)

\begin{tabular}{lrr}
\hline Worker or producer cooperative & 20.448 & 35.1 \\
\hline Building cooperative & 10.357 & 17.8 \\
Social coo66perative & 9.617 & 16.5 \\
Agricultural cooperatives & 4.746 & 8.1 \\
Cooperatives of agricultural job & 2.250 & 3.9 \\
Consumer cooperative & 1.334 & 2.3 \\
Transport cooperatives & 1.128 & 1.9 \\
Burial cooperatives & 929.000 & 1.6 \\
Other cooperatives & 5.786 & 12.6 \\
Total & 58.236 & 100.0 \\
\hline
\end{tabular}

Source: Elaboration Institute G. White Tagliacarte on data cooperatives of the ministry of the productive activities

\section{THE FINANCIAL MANAGEMENT IN THE SOCIAL COOPERATIVES}

The financial management is a critical element in all types of enterprise. The characteristics of the financial instruments-its typology and date of expiration-are fundamental to obtain a long run financial equilibrium (Teece, 1980). It is known that a temporary financial disequilibrium could not weaken the economic equilibrium, nevertheless a bad financial management in a long period damage the economic performance (An enterprise characterized by economic balance should not has too much difficulty in finding financial resources. Nevertheless, if the financial imbalance became persistent (this assumptions is realistic for a social enterprises where there are prevalence of activities with public entities), with the increase of liabilities increase the average cost of such liabilities. In a social enterprise the margin income is usually not large and in the long run the excessive weight of financial charges could lead to an economical imbalance. Moreover, a social enterprise is featured by exchanges with the market; so, it is necessary a good management of the liquidity in order to not compromise the exchanges with the suppliers (Messina, 2003; Nyssens, 2006).

The finding of resources to activate the operative cycle, requires a hard attention on the amount and typology of such resources, in order to support correctly the process of acquisition of the current assets. These assets are indispensable for the maintenance of the quantitative and qualitative level of the supplying services. So, the quality of the financial management is considered more important in the social enterprises, whereas the quantitative and qualitative level of the offer may increase the level of social welfare.

In the social enterprises the attention of the management is often addressed to the social sphere, with an insufficient entrepreneurial culture and the luck of financial management knowledge (The consequence of such insufficient financial culture is, according with Pace
(2004), the absence in the no profit organizations of a specific function dedicated to the financial management) (Zimmermann, 1999).

A not very careful financial management could weaken the social enterprise in a context in which the traditional financial intermediaries and particularly the banks, consider more uncertain the solvency of the social organizations; the worse profile of risk assigned to these organizations is translated in rationing of the credit with the increase of the interest expenses (Poo-Inna et al., 2014).

According to Manelli (1996), the banks (Cenni, 2005) assign a worse level of risk to the social cooperatives due to:

- A strong dependence from the human factor, above all for the operating activities

- The insufficient presence of fixed assets, to be used by banks as real guarantees

- The lack of a detailed planning for the investments, with the forecasts of the economical and productive opportunity derived by such investments

\section{ETHICAL FINANCE AND FINANCIAL INSTRUMENTS FOR SOCIAL COOPERATIVES}

\subsection{Evolution of ethical Finance}

During the last few years the Third sector in Italy has assumed considerable dimensions, although not comparable to those of other European countries. Recent studies have pointed out a composition which is based above all on organizations of small-medium dimensions, both in terms of workers and of yearly turnover, which are characterized by a slow rhythm of economic increase and organizational development (Borzaga and Defourny, 2001). 
In the last years in Italy there was an increasing attention towards the ethical finance (Perrini et al., 2002). The development of an ethical finance (Bocciato, 2000), although it is originated from the will to support the social responsible development, at the moment, seems not to support a substantial resolution of the financial needs related with the Third sector.

At its first stage of evolution, the ethical finance has been considered above all as the participation of financial intermediaries in support of those donations which are destined to deserving initiatives in the charity field. The instruments and the used modalities of financing may be considered substantially as beneficence, without a real participation of the financial institution on the credit rating of the grantee. Such instruments, which are similar to those appeared in the United States in the Seventies, were represented above all by the donation to solidarity initiatives of part of the credit interests of the account holders and the proceeds deriving from the investment funds. The ethical finance "was practiced" by the traditional financial intermediaries like an active engagement towards the increase of the flows assigned to social initiatives, by soliciting their own customers to the renunciation to quotes of the proceeds in order to destine them to various sort of charity. Such participations were and are basically considered as being marketing instruments turned to the improvement of the offerer's image, rather than instruments for a socially responsible development. As what regards the offeree, the selection is therefore referred exclusively to the social merit and to "the media appeal" of the proposed initiative, which are supported entirely by means of liberal distributions (Azril et al., 2014).

In consequence of the pressures that the environmentalist and pacifist groups have turned towards the public opinion in order to oversee the employment of the recourses by the financial intermediaries, a second step of the ethical finance has developed, which might be defined as "negative selection" (Schena, 2003). The increasing attention of the public opinion towards the ethical business, brings to the offering of investment instruments which are proposed as being ethical, since they exclude from their own investments those enterprises or activities which are non ethic.

Later on, it is possible to identify a phase in the development of the ethical finance which may be defined as "positive selection". In this phase we move from the penalization-exclusion from the investments-of nonethical enterprises, to an investment rating based also on the ethical business. This new approach to the ethical finance has been supported also by the evidence, in the long term, that it does not exist any statistic correlation between ethical business and poor performance. Indeed, it has more and more spread the conviction that in the long term the balanced growth of the economy, obtained by means of responsible behaviours, advantages both the enterprises and the investor. So the problem becomes to identify parameters, economically valid, which permit to correctly evaluate the relationship between economic increase and social responsibility (Marcon and Tieghi, 2000; Marano, 2006; Matacena and Marano, 2006).

\subsection{Financial Instruments in the Companies Legislative Reform}

\subsubsection{Equity}

The low capitalization often represents a characteristic of the social cooperatives (Manelli, 1996). In view of the application of Basel 2, the insufficient presence of equity capital is one of the elements which can penalize the rating process, since it may be interpreted as a structural weakness (Marotta, 2004). Not always the members are ready to support the entity and the times of the equity increase. In order to favour the finding of financial resources, also in the form of venture capital, the legislator of the society reform of 2003 has broadened number and typology of the financial instruments on hand of the cooperative societies. It has been asserted that, with the increase of the borders of the two traditional instruments for the finding of financial resources, the shares and the bonds, the legislator has disciplined the grey zone which is interposed between the two institutes (Capelli, 2004).

As far as the shares, the reform expressly establishes the possibility to create special categories of "atypical" shares, also providing the possibility to determine, through the statute, the contents of the shares of the different categories (Cusa, 2003; Lamandini, 2003; Genco, 2006, Iengo, 2006). For the first time the right of voting connected to the possession of the shares, becomes a variable element, which can be limited or quite suppressed, without any administrative or patrimonial consideration. Such forecast might be particularly interesting for the social cooperatives: The possibility to reduce the voting rights is likely to allow putting the equity capitals at disposal of certain categories of financing subjects, without the fear, which is so often a cultural heritage of such groups, to compromise their own social nature.

A further innovative forecast of the reform is the institute of the "tracking stocks" or tracking shares: Such financial instrument, already famous in other countries, are Shares issued by a company which pay a dividend 
determined by the performance of a specific portion of the whole company. In this way the legislator would to favour the participation to equity for the financial investors, as the ordinary members too, which are interested to finance only specific activities of the whole cooperative. Moreover, such instrument could favour processes of business combination between cooperatives which, although carrying out activities so varied amongst themselves, are interested in the realization through the concentration of economies of scale, particularly for the general cost, by keeping on to dedicate each of them to the specific core business.

\subsubsection{Loan}

The social cooperatives in Italy have traditionally had to interact, for the resolution of the problematic of financial management, above all with banking system (Mazzoli and Rocchi, 1996, Fiorentini, 1996). The difficulties currently encountered are the kind of difficulties concerned with the generality of the PMI: Credit rationing, difficulty in supplying the guarantees, undercapitalization. Within the traditional instruments of indebtedness, the most common ones to the social cooperatives are:

- In the short term financing, the credit line and the advance on commercial credit, respectively for the 88 and $68 \%$ of the cooperatives that have obtained financings

- For the long term financing (Cesarini and Barbetta, 2004). The mortgage loan, the subsidized loans by special laws and the leasing, respectively, for 70,29 and $21 \%$ of the subjects that have activated tools of long term financing

A mixed financial instruments is deriving by the experience of profit organizations and is finding application also in non profit. The equity loans are introduced in Italian law by the act of 5 October $1991 \mathrm{n}$. 317. The equity loan is represented in triangular relationship between the bank, the financed enterprise and the thirds parties (usually the members). The financed society is obligated to correspond to the bank, the amortization quote, the interests and a percentage of the net income. As well as, the members, which give the loan guarantee, have to supply to the society the necessary resources for the loan repayment. The operation is configured as an advance of the equity subscription. The advantage for the members consists in delay the financial engagement, while the advantage for the enterprise consists in obtaining immediately the necessary resources for its activities. The loan is granted in relation to a program of activity, finalized to the constitution, to the development and the business restructure and for environmental investment, for the technological innovation and for employment support.

\section{AN INSTITUTIONAL INVESTOR DEDICATED TO SOCIAL COOPERATIVES: CFI}

\subsection{History}

Cooperazione Finanza Impresa is a private equity investor which since twenty years is dedicated to worker cooperatives and social cooperatives. CFI was created in 1986 at the initiative of the three major cooperative associations in order to manage the Fondo Marcora, which was set up to safeguard employment through the creation of companies.

In the first phase of activity CFI it has invested approximately 80 million euro in equity of the 160 worker cooperatives constituted by dependent of companies in crisis situation (operations of workers/employment buy out) and overall, promoted stable employment for about 6.000 workers.

In a changed economic-industrial scenario, from 2003 onwards, CFI redefined and broadened its own investment strategy: Indeed, it began to finance start up, development, consolidation and re-positioning projects of companies that have been constituted as a cooperative. Its operational instruments take the form not only of equity, but also financing to support fixed investments.

Furthermore, CFI makes available, to the companies, a human resource team that represents a good mix of experience and knowledge in the area of financial planning and management control.

It participates to the enterprise risk, supports the investments, it guarantees to management the constant support in the strategic decisions and the operating choices (Oster, 1995). It has assets of 108 million euro and a portfolio to the 31.12.2005 composed from 55 cooperatives.

\subsection{Mission}

The mission of CFI it can be synthesized in following objectives:

$>$ To support the success of the cooperative company model

$>$ To stimulate entrepreneurship and forward planning capacities of the worker members

$>$ To promote and increase employment

$>$ To enhance the capacity to grow and compete

The target sector are industry and the services. Other requirement for financing is the dimension within the 
parameters for the European SME; may be considered SME, in extreme synthesis, the autonomy enterprises which respect the following parameters:

\begin{tabular}{llll} 
& \multicolumn{3}{c}{ YEARLY } \\
& EMPLOYMENT & TURNOVER & ASSETS \\
MICRO ENTITIES & $<10$ & $<2 \mathrm{~mL} / €$ & $<2 \mathrm{~mL} / €$ \\
SMALL ENTITIES & $<50$ & $<10 \mathrm{~mL} / €$ & $<10 \mathrm{~mL} / €$ \\
MEDIUM ENTITIES & $<250$ & $<50 \mathrm{~mL} / €$ & $<43 \mathrm{~mL} / €$
\end{tabular}

If the entity take part in a business group, the respect of the parameters comes verified considered in combined way the group of enterprises.

In the present Fig. 1, we can see the comparison between Ethical Finance and CFI' target:

\subsection{Financial Instruments Proposed}

As far as the equity subscription is concerned, CFI provides equity capital by taking a minority shareholding as a financing member. This status gives it administrative and asset financial rights, as governed by the civil code, the statutes and an appropriate regulation.

The maximum value of its participation is equal to the cooperative's equity; the limit is necessary in order to provide not excesses resources and for not acquire the control of voting rights. This limit can be exceeded in case of consistent own reserves; in such case the maximum value of the equity subscription may increase until a double amount of cooperative's equity (The maximum amount of CFI's participation may be determined in the following: Example 1. capital stock 100+reserves 60+social loan $10 \rightarrow$ then the maximum value of cfi's participation will be 170 . Example 2 capital stock $100+$ reserves $60+$ social loan $50 \rightarrow$ then the maximum value of cfi's participation will be 200).

The participation of CFI to cooperative's equity has temporary character. The terms of repayment are:

- Within the 5 th year for $25 \%$ of the equity loan;

- Within the 10th year for the remaining $75 \%$.

The disinvestment plan is correlated to the characteristics of the project and the company's economic/financial feasibility plan.

CFI integrates private equity deals by financing fixed investments with:

- Loans

- Equity loan

- Bonds, convertible bonds

- Debt guarantee

- Building leasing (Trough a specific spin off entity, Picoleasing)

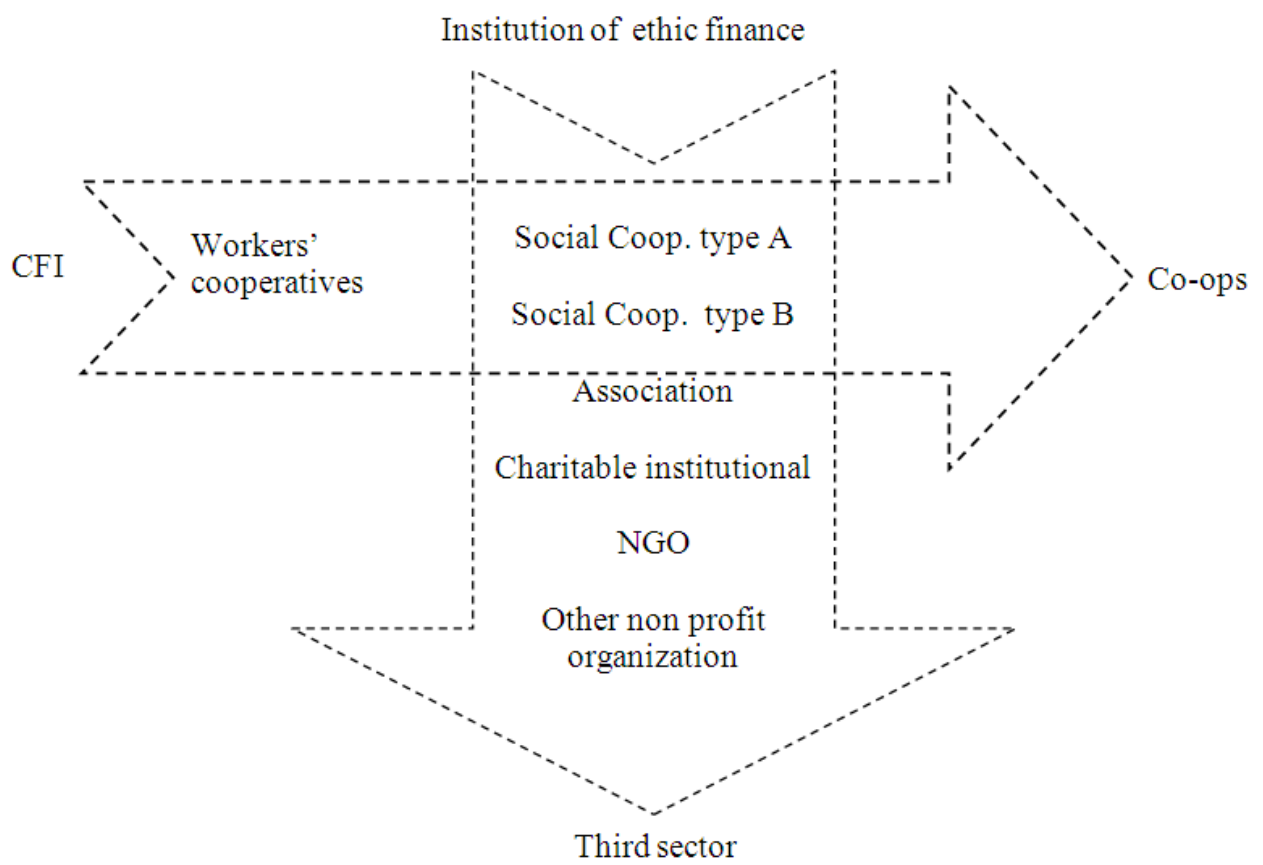

Fig. 1. (Our elaboration) 
The financing must be finalized to support a new fixed investments plan, in order to obtain a substantial development of the cooperative. CFI does not offer short term financing, because its objective is support strategic choice and the consequent financial needs.

Furthermore, CFI makes available, to the companies, a human resource team that represents a good mix of experience and knowledge in the area of financial planning and management control.

The activity of CFI may assume, in the specific one of the social cooperatives, a relevant role for sizedevelopment, because CFI, with its services, can increase the financial and managerial resources.

\section{THE FINANCIAL ANALYSIS: CASE STUDIES}

The financial statement can support the recognition and the evaluation of economics and financial results, in an administrative period. Obviously, the evaluation of the results has influenced by subjective factors, as the personal requirements of the subject that carries out the evaluation.

The financial analysis is a complex activity, widely used, based on formal and techniques rules elaborated from the doctrine, directed to the evaluation of the management and of the business. The financial analysis do not supply directly the evaluations, but it supply the useful informations to evaluate the quality of management and the state of the firm equilibrium (Phalavani and Ezzati, 2014).

Such type of analysis is carry out on the assumption that the simple observation of financial statements is insufficient to understand the business fundamental (Marano, 2006). Therefore, is necessary to use reclassifications, margin and ratios which give a better representation of the business performance. The information derived from such indicators naturally neither explain the reason of economical or financial imbalances, nor can suggest the "therapy". Nevertheless, such informations give the signal of the problems in a useful time to search solutions and to analyze the effects of each decision.

The financial statement data could not be immediately useful for the required informations; according with the financial analysis objective, is necessary a reclassification. In the present work, it has used a reclassification of the assets and liabilities with reference to their attitude to create/drain liquidity. We intend for the followings aggregates of assets:
- Working Capital (Current Assets): It includes the assets that have the attitude to create liquidity within twelve months; in such aggregate we locate the Inventory, Accounts receivables (credits) Cash and Cash equivalent

- Fixed Assets: It includes the long run investments that have the attitude to create luiquidity later than twelve months such aggregate include Property, Plant and Equipment, Intangible assets

While the liabilities are reclassified in:

- Current Liabilities: It includes the sources of financial resources in the short run; they have the attitude to drain liquidity within twelve months

- Non Current Liabilities: It includes the financial sources with expiration limit later than twelve months

- Equity: It includes the sources without expiration time

\subsection{Financing Social Cooperatives by Participative Loan}

The first analysis is related to a social cooperative, a type, operative in the field of the residential and semiresidential care services both for children and for adults. It is part of a group of 14 social cooperatives, one association and one organization of voluntary services. The strategies of development include the research of a financing in order to buy and restructure a build to destine to the organization of a new residential service for children. Other required expenses are related to the necessary equipment and to the training of the workers. The financing is provided by CFI by a participative loan. This mixed form of equity/liabilities attribute to CFI administrative rights, includes the choice of a member of the board of directors and an accordance for a minimum remuneration by net income of $3.5 \%$.

\subsubsection{The Solidity Analysis}

This analysis has the aim to investigate on the configuration of the Non Current Assets and Liabilities, in order to verify the existence of a financial equilibrium in the long period. With this kind of analysis, therefore, we want to evaluate the effects on the long term financial structure by using the financial instrument "participative loan". If an enterprise has the characteristic of the solidity, it has the possibility to go beyond the situation of a short term financial imbalance. In fact, its sound financial structure agrees to absorb the negative effects of such financial imbalance without to weaken the going concern.

The ratios and margins used are: Primary difference (E-NCA); Secondary difference (E+NCL-NCA); Solidity Ratio (E+NCL/NCA). The Primary difference 
indicates the capacity of the social cooperative to finance the investments in non current assets, that may be considered the strategic investments for the achievement of the entrepreneurial objectives, with the own resources, with those sources that haven't a time of expiration.

It's known that often the fixed assets can't be covered only with equity; so we extend the analysis to the secondary difference. Such indicator shows the relationship between the time of the financial return by investments and the time of expiration of the sources. This correlation, allows the evaluation of the capacity of the enterprise to realize a financial equilibrium in the long term.

The differences supply absolute values; they can support a comparison, for the same enterprise, between different period. However, it is important to evaluate the financial structure in a relative way, in order both to allow a comparison between different enterprises both "to sterilize" the effects on the absolute values of the dimensional growth. We has chosen to use therefore also the Solidity Ratio.

\subsubsection{Autonomy Analysis}

It represents a further investigation of the solidity aspects. The sources that do not increase the financial risk for the enterprise are evaluated also in relationship with the possible dependence that such sources create towards third subjects. This aspect is investigated by the distinction between internal resources (resources by equity) and external resources (resources by debt). Obviously the more is the dependence from external resources, the more is likely that in the decision making process could have some influence the objectives of third subjects, increasing the risk that the organization should take different decisions from those optimal.

The ratios and used are: Debt to Equity Ratio (Df/E), Average Cost of financial debts (I/Df) (The acronyms used are: Df for Financial (onerous) Debt; I for Interest expenses).

In the autonomy analysis we chose as a useful information the Debt to Equity Ratio; it expresses the relation between the financial debts and the resources invested from the partners in the enterprise. The more the relation will raise, the less should be the autonomy in the decision making process. In fact, it should be logical that with the growth of Debt should raise also the attempt to control of third subjects in the decision making, in order to induce the management to have behaviours that guarantee them on the capacity of payback.

Other important indicator used is the Average Cost of financial debts. The information related to the autonomy of such indicator is expressed by the capacity of the enterprise to find alternative sources. On the assumption of an individual rationality, a high profile of risk should be associate with a high debt, with a smaller number of intermediaries available to finance the enterprise. Instead, a low debt cost should indicate a low risk profile, with more suppliers.

Moreover this indicator could supply information about autonomy, about the liquidity and about the earnings. It is obvious that a lower weight of the debt cost increases the potential margin. In the financial finding it is supposed that the choices that decrease the average cost of the indebtedness enlarge the number of the financial institutions and so the financial choices available. Because of this enlargement, it should be more simple to change the financial provider, with obvious impact on the autonomy. In the liquidity analysis, of course the lower rate allows to obtain, with the same expense, more financial resources.

\subsubsection{Liquidity Analisys}

This kind of analysis considers the financial equilibrium with reference to the short time. An operating firm has a large number of payments to make on a regular basis. The liquidity is an important indicator for the short-term solvency.

Such type of analysis is considered extremely important in each enterprise, also in a social enterprise. Those organizations are often characterized from hard problems of liquidity. In effects the typical financial structure in a social enterprise is characterized by a low level of fixed assets and equity; this situation do not allows an easier research of financial resources from debts. Moreover, the income statement shows the prevalence of monetary costs, with a low capacity of self-financing.

The ratios and margins used are: Net Current Assets (CA-CL); Treasury Margin or Net Liquid Assets (LA+CCL) (The acronyms used are: CA for Current Asset, CL for Current Liabilities, LA for Liquid Asset (include Cash and equivalent, Bank deposit, financial instrument that can be immediately liquidated), $\mathrm{C}$ for Credits).

The Net Current Assets, if it has positive amount, expresses the short term solvency of the enterprise; it is represented by the difference between the current assets, that should guarantee positive cash flows within twelve months and the current liabilities that should instead drain cash in the same period. A positive NCA indicates that the enterprise has sufficient cash flow to satisfy both maturing short term debt and forthcoming operational expenses. Nevertheless, the NCA measurement is able to be misleading for l' analysis of the liquidity in absence of an analytic analysis on the Inventories: Often in this accounting data there are 
elements that cannot be liquidated because of their obsolescence. For the difficulty in evaluating inventories liquidability, the analysis on NCA are furthered with the calculation of the Margin of treasury. This margin is built excluding the inventories from NCA. If such margin is positive, then the enterprise will be able to pay the short period debt by the present liquidity and by the positive cash flows generated by short term credits.

The diagram of reclassification and the main margins used can be represented in the following Fig. 2.

\subsection{First Step of Analysis: The First Case Study}

In the following Table 1, the spread of cooperatives in the national context is shown, also the different types of cooperatives are highlighted.
Instead, In the Table $\mathbf{2}$ is synthetically reported the financial structure, during the period 2004-2006, of a social cooperative analyzed: The 2004 represents the year before the operation of financing by CFI participative loan. In the second part of 2005 it began the financial operation, so 2006 represents the first period that make evidence at the modified financial structure.

The margins and the ratios of the financial analysis are shown in the following Table 3. The table draw near in three columns the values of the ratios in the years 2004, 2005 and 2006, in order to appreciate in a comparative way the different values.

The Primary difference emphasize a worsening in 2005 with a partial inversion of the trend in 2006. The Secondary difference also register a worsening in 2005 with a substantial inversion of the trend in 2006.

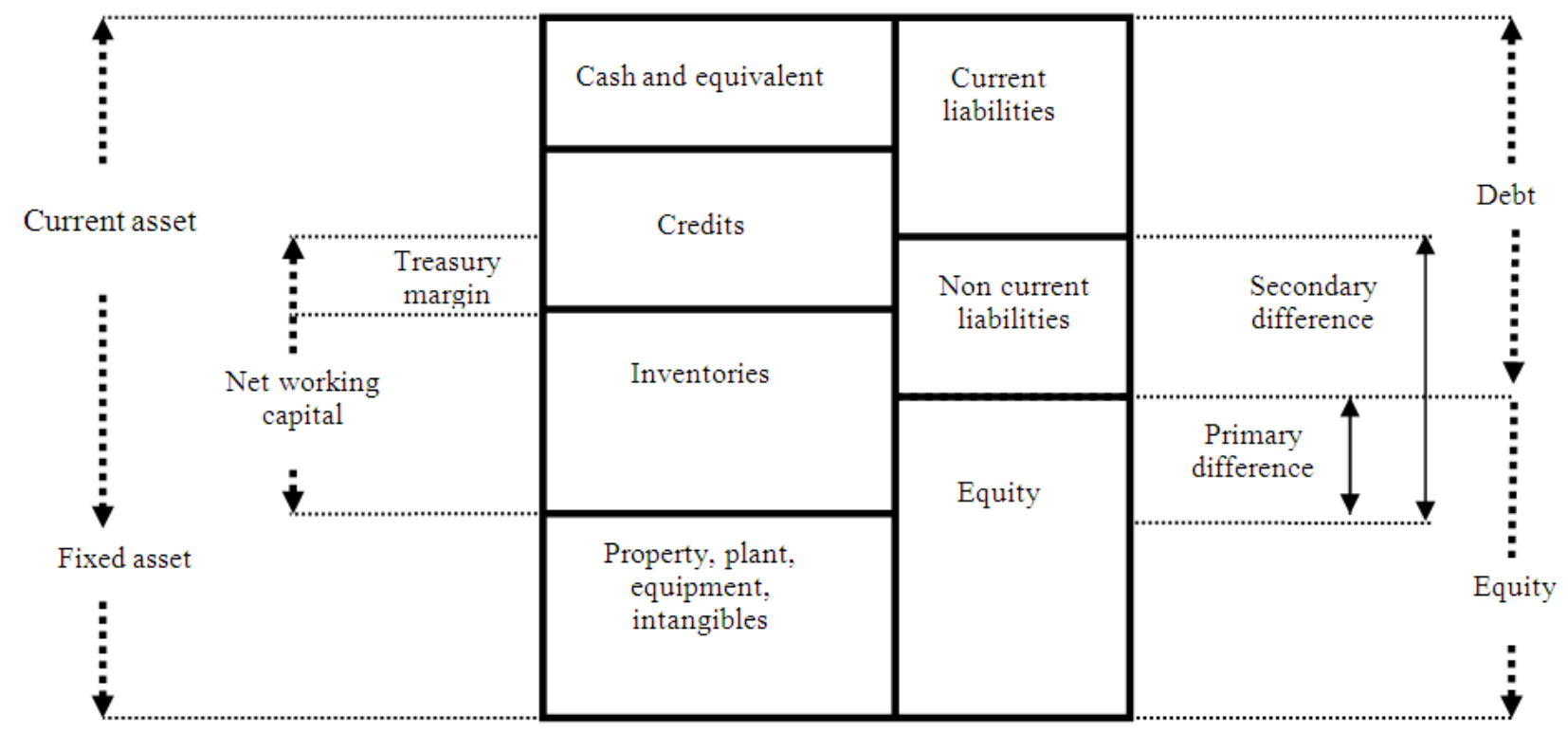

Fig. 2. (Our elaboration)

Table 2. The financial structure, during the period 2004-2006, of an analyzed social cooperative

\begin{tabular}{llllllll}
\hline & 2004 & 2005 & 2006 & & 2004 & 2005 & 2006 \\
\hline Fixed asset & $2.239 .559,00$ & $4.010 .004,00$ & $3.823 .607,06$ & Equity & $1.346 .130,00$ & $2.583 .222,00$ & $2.615 .959,21$ \\
Current asset & $1.520 .792,00$ & $1.979 .291,00$ & $1.865 .461,28$ & $\begin{array}{l}\text { Non current } \\
\text { liabilities }\end{array}$ & $1.012 .081,00$ & $1.422 .388,00$ & $2.479 .432,86$ \\
& & & & $\begin{array}{l}\text { Current } \\
\text { liabilities }\end{array}$ & $1.402 .140,00$ & $1.983 .685,00$ & $593.676, \quad 27$ \\
Total asset & $3.760 .351,00$ & $5.989 .295,00$ & $5.689 .068,34$ & $\begin{array}{l}\text { Total equity } \\
\text { and libilities }\end{array}$ & $3.760 .351,00$ & $5.989 .295,00$ & $5.689 .068,34$ \\
& & & & & &
\end{tabular}

Source: Elaboration Institute G. White Tagliacarte on data cooperatives of the ministry of the productive activities 
Table 3. Values of the ratios in the years 2004, 2005 and 2006

\begin{tabular}{llll}
\hline & 2004 & 2005 & 2006 \\
\hline Primary difference & $-893.429,00$ & $-1.426 .782,00$ & $-1.207 .647,85$ \\
Secondary difference & $118.652,00$ & $-4.394,00$ & $1.271 .785,01$ \\
Debt to equity ratio & 1,053 & 0,999 & 1,333 \\
Leverage & 0,648207083 & 0,500835839 & 0,853020602 \\
Average cost of debt & $2,96 \%$ & $2,03 \%$ & $1,88 \%$ \\
Liquidity & $72.642,00$ & $74.981,00$ & $151.813,71$ \\
Net current asset & $118.652,00$ & $-4.394,00$ & $1.271 .785,01$ \\
Net liquid asset & $110.655,00$ & $-8.050,00$ & $1.262 .085,01$ \\
\hline
\end{tabular}

Source: Our elaboration

Such course can be explained by the growth of the equity in 2005, realized through the CFI participative loan and by a strong expansionist strategy of investments in fixed asset. On the whole, is possible affirm that the enterprise have carried out a rebalancing between the short-term liabilities and to long term liabilities, in order to obtain a better relationship between the asset and liabilities, in a situation of substantial solidity. It is emphasized in fact a considerable growth of the investments in Fixed Asset, while there are small variations in the current asset.

In the liquidity analysis, the choice of inadequate financial instruments shows very dangerous signals in 2005: In such period in fact both the Net Current Asset and the Margin of treasury take on negative values: The short term debt come to expiration while the assets could not guarantee sufficient cash flow. The participative loan, started in 2005, assure the inversion of the trend in 2006, with a balanced situation of liquidity.

A very important effect by using the tool analyzed is the significant reduction of the average cost of the debt. This ratio shows a decrease in the interest expense of about $34 \%$. This reduction could be explained with the better capitalization of the cooperative after the participative loan. It's known that the cost of the debts has an inversely proportion with the entity of the equity capital. The increase in equity is considered as an important signal of the quality of the management. If the shareholders increase their investment, then the forecasting on earnings are supposed as positive. The lower risk profile assigned due to the increase of equity capital allows a reduction of the cost of debt capital.

\subsection{Second Step: Extension of Financial Analysis to Other Social Co-Ops}

After analysing the results of the first case study, the analisys has been extended to the other social cooperatives that have activated with CFI a participative loan. The further investigation has been conducted always on a three years period of observation, in order to compare with others case studies the results obtained in the first analysis (Chantachan, 2011).

The social cooperatives that have activated such financial tool since at least three years, at the moment, are ten. The data are compared for the period of three years 2005-2007 (In the first case study the analysis is referred to the period 2004-2006. For such case it has updated the analysis with the data of 2007).

Significant results arise with reference to the average cost of the financial debts. According with the different dimension of the ten cooperatives, the assessment is based on the variation (percentage) of the rate in the three years analyzed. The size of the variation in the average cost of debt in each cooperative is reported in the following Table 4.

The second step of analysis emphasizes that the reduction in the Average Cost of the Debt is confirmed in the others social co-ops financed by a participative loan, even if with a lower rate than one registered in the first case analyzed. If the extreme values are excluded from the average, the arithmetic mean of the variations in the average cost of the debt is calculated in the 10,65\%: Considering the ten cooperatives observed, these benefited of an average reduction of $10,65 \%$ on the cost of the debts. Furthermore, within the ten cooperatives there is one of them that has contracted a build leasing, choosing the accounting solution recommended by the international accounting standards (The International Accounting Standard n. 17, Leasing, require for such operations the financial method of accounting: The asset is recognized in the balance sheet, as a fixed asset, while the debt towards the leasing company is recognized as a liabilities; in the income statement instead arise the interest expenses contents in the rent of lease and the amortization of the asset). The recognition criteria influences in this case with sensitive effects the interest expenses recognized in the income statement and consequently the average cost of debt: If this case is excluded, the average reduction in the cost of the debt, in the other nines cooperatives, is around the $15 \%$. 
Table 4. - Variation in the Average Cost of Debt after 1 year.

\begin{tabular}{lrlr}
\hline Variation in the average cost of debt (positive for decrease) & Averages - I Observation \\
\hline Case study 1 & $37,62 \%$ & Arithmetic mean & $9,83 \%$ \\
Case study 2 & $51,08 \%$ & Without the extreme & $10,65 \%$ \\
Case study 3 & $32,48 \%$ & & \\
Case study 4 & $-22,53 \%$ & Median & $13,11 \%$ \\
Case study 5 & $-6,25 \%$ & & \\
Case study 6 & $-28,76 \%$ & & $14,89 \%$ \\
Case study 7 & $-12,55 \%$ & Without the leasing operations & \\
Case study 8 & $54,19 \%$ & & \\
Case study 9 & $-41,05 \%$ & $34,10 \%$ & \\
Case study 10 & &
\end{tabular}

Source: Our elaboration

Table 5. Variation in the Average Cost of Debt after 3 year.

\begin{tabular}{lrlr}
\hline Variation in the average cost of debt (positive for decrease) & Averages - II Observation \\
\hline Case study 1 & $60,29 \%$ & Arithmetic mean & $16,18 \%$ \\
Case study 2 & $91,93 \%$ & Without the extreme & $19,45 \%$ \\
Case study 3 & $-26,39 \%$ & \\
Case study 4 & $-69,24 \%$ & \\
Case study 5 & $-27,10 \%$ & \\
Case study 6 & $-24,45 \%$ & \\
Case study 7 & $60,73 \%$ & \\
Case study 8 & $-82,44 \%$ & \\
Case study 9 & $23,86 \%$ & \\
Case study 10 & &
\end{tabular}

Source: Our elaboration

\subsection{Third step: Extension of Financial Analysis to the Medium-Term}

The third step of analysis regards the medium-term effects. The results showed in Table 3 affect the effects on average cost of debt after one year. In a second step, in order to observe the effect in the medium term on the financial structure, we analyse the increase/reduction in cost of debt in the three years followings the financial operation (for most of the case studies 2007, 2008 and 2009).

By analysing the results of the third step (Table 5), we can affirm that the reduction in the cost of debt is an effect not limited to the short-time. After three years from financing operation the average cost of debt, in the cooperatives analysed, detects a further reduction. After one years the decrease in the ACD was about of ten points; in the followings years the cooperatives detect a lower level of financial expenditures, with a subsequent further decrease that reach and overcome the sixteen points.

\section{CONCLUSION}

The economic analysis in the social enterprises suggests some elements of criticality related to the weakness of managerial capacity and to the lack in the care of the financial management. The financial structure gives evidence of a very low level of equity capital, with difficulties in the achievement of economical and financial balance. In those organizations the members are not always ready to support the entity with an increase of equity capital.

With the aim to support the finding of financial resources, the recent companies' legislative reform of 2003 has enlarged in number and typology the financial tools available for the cooperatives.

An innovative but not yet diffused financial tool, which could be useful and profitable for the social enterprises, is the participative loan. It consists in advance equity capital that, in a period of ten/fifteen years must be "repaid" with a share re-buying. The purchase of the share could be done by the organization (with the retained earnings), by the same members or by other subjects (so they become new members). The advantage for the members consists in delaying the supplying of financial resources, while the enterprise obtains immediately this resource.

The participative loan could be able to solve the problem of the low capitalization in the social cooperatives. It may assure the availability of necessary 
resources above all in case of investments in fixed assets by equity capital.

Particularly, it is necessary to emphasize that the role of the financial intermediate (CFI in the analyzed case studies) is developed by becoming "partner" of the social enterprise.

The impact on the financial structure of the participative loan could be explained, on the basis of the case studies, by the following statements:

- To improve the financial structure both in the long than in the short period

- To obtain a reduction of the average cost of debts and an enhancement of the liquidity

- To balance the investment time with the expiration time of the liabilities

The better obtained financial structure allows the assignment of a lower risk level in the rating process, with a consequent reduction.

\section{REFERENCES}

Airoldi, G., 1996. Le aziende non profit: Definizioni e classificazioni, in AA.VV., Le aziende non profit tra Stato e Mercato-Atti del Convegno AIDEA, Roma, 1995, Clueb, Bologna, 1996.

Azril, M.S.H., U. Jegak, M. Asiah, A.N. Azman and A.S. Bahaman et al., 2014. Can quality of work life affect work performance among government agriculture extension officers? A case from Malaysia. J. Soc. Sci., 6: 64-73. DOI: 10.3844/jssp.2010.64.73

Cesarini, F and G.P. Barbetta, 2004. La Finanza Specializzata per il Terzo Settore in Italia. 1st Edn., Bancaria Editrice, Milano, ISBN-10: 8844906341, pp: 134.

Bocciato, F., 2000. Finanza Etica e Impresa Sociale. 1st Edn., Il Mulino, Bologna.

Borzaga, C. and J. Defourny, 2001, The Emergence of Social Enterprise. 1st Edn., Routledge, London, ISBN-10: 0415253012, pp: 383.

Capaldo, P., 1996. Le Aziende Non Profit tra Stato e Mercato. 1st Edn., CLUEB, Bologna, ISBN-10: 8880914111, pp: 499.

Capelli, I., 2004. I Nuovi Strumenti Finanziari dopo la Riforma del Diritto Delle Società di Capitali. 1st Edn., Insubria University Press, ISBN 978-8889882-01-6, pp: 70
Cenni, S., 2005. C'e Qualcosa di Speciale nel Rapporto Banca e Impresa Cooperativa? Relazione presentata al Convegno "La Finanza per il Terzo Settore", Forlì-25 Novembre 2005, Camera di Commercio di Forlì e Cesena.

Chantachan, S., 2011. A Comparative study of the development model in education and religion management process between Thailand and Lao. J. Soc. Sci., 7: 209-212. DOI: 10.3844/jssp.2011.209.212

Cusa, E., 2003. Strumenti finanziari e soci finanziatori nelle cooperative. Proceedings of the Gli Statuti Delle Imprese Cooperative Dopo la Riforma del Diritto Societario, (FDS' 03), Associazione Disiano Preite. Università degli Studi di Bologna, 7 febbraio.

Defourny, J., 2001. From Third Sector to Social Enterprise in The Emergence of Social Enterprise. London: Borzaga, C. and Defourny, J., Routledge.

Desrochers, M. and K.P. Fischer, 2005. The power of networks: Integration and financial cooperative performance. Annals Public Cooperative Econom., 76: 307-354. DOI: $10.1111 / \mathrm{j} .1370-$ 4788.2005.00281.x

Evers, A. and J.L. Laville, 2004. The Third Sector in Europe. 1st Edn., Edward Elgar Publishing, Cheltenham, ISBN-10: 1843769778, pp: 266.

Fici, A., 2005. Finalità e organizzazione delle cooperative sociali: Alcune indicazioni dal nuovo diritto societario. Beni Comuni-Quarto rapporto sulla cooperazione sociale in Italia, Edizioni Fondazione Giovanni Agnelli, Torino.

Fiorentini, G., 1996. Il finanziamento delle aziende non profit. in AA.VV., Le aziende non profit tra Stato e Mercato-Atti del Convegno AIDEA. Roma, Clueb, Bologna.

Forestieri, G., 2002. Il nuovo diritto societario Un Commento dal punto di vista della finanza, Relation to conference"Il nuovo diritto societario tra società aperte e società private. Varese, 20-21.

Genco, R., 2006. Finanza cooperativa e ruolo dei Fondi mutualistici, I nuovi strumenti finanziari delle società cooperative: Verso il mercato dei capitali di rischio. Legacoop Toscana, Firenze, 3 luglio.

Iengo, M., 2006. Gli strumenti finanziari per le società cooperative dopo la riforma del diritto societario. Relation to conference"I nuovi strumenti finanziari delle società cooperative: Verso il mercato dei capitali di rischio. Legacoop Toscana, Firenze, 3 luglio. 
ISTAT, 2003. Le cooperative Sociali in Italia-Anno 2001. 1st Edn., Statistiche in Breve, Roma.

ISTAT, 2014. Nono censimento dell'industria e dei servizi e delle Istituzioni non profit-Anno 2011. Edizioni Istat, Roma.

Lamandini, M., 2003. La riforma della struttura finanziaria delle cooperative: Azioni e ibridi verso la quotazione. Relation to conference"La riforma del diritto delle cooperative", Bologna, 7 febbraio.

Lionzo, A., 2002. La Cooperativa Sociale: Originalità della Formula, Economicità e Strumenti di Analisi. Economicità e Strumenti di Analisi. 1st Edn., Franco Angeli, Milano, ISBN-10: 8846442709, pp: 325.

Manelli, A., 1996. La Gestione Finanziaria Dell'Impresa Cooperativa. 1st Edn., Edizioni Seam, Roma, ISBN10: 8886088655, pp: 304.

Marano, M., 2006. L'accountability e i processi informativi dell'impresa sociale alla luce del d. lgs. 115/2006, Working paper n. 38, dicembre.

Marotta, G., 2004. La finanza del terzo settore e Basilea 2. Relazione presentata al convegno "Finanza strutturata e non profit: Nuove opportunità aspettando Basilea 2, ISSAN. Trento, 17-18 giugno.

Matacena, A., 1990. Gli obiettivi delle cooperative, in Sorci C. Imprenditorialità e cooperazione. Giuffrè, Milano.

Matacena, A., 1999. Le aziende non profit. Una definizione degli attori del terzo settore. Scenari e strumenti per il terzo settore, Egea, Milano.

Matacena, A. and M. Marano, 2006. Accountability e social reporting nelle cooperative mutualistiche. Rivista della Cooperazione. n. 2, Roma.

Mazzoli, M. and E. Rocchi, 1996. La finanza delle cooperative. Liocorno Editore, Roma.

Marcon, G. and M. Tieghi, 2000. Sistema informativo e misurazioni economiche nelle aziende non profit. Aziende non profit, Le condizioni di sviluppo, Egea, Milano, 2000.

Messina, A., 2003. Denaro Senza Lucro. Manuale di Gestione Finanziaria Per il Terzo Settore. 1st Edn., Carocci Faber, Roma, ISBN-10: 8874660332, pp: 272.
Nyssens, M., 2006. Social Enterprise: At the Crossroads of Market, Public Policies and Civil Societies. 1st Edn., Rutledge, London, ISBN-10: 113418218X, pp: 352.

Oster, S.M., 1995. Strategic Management for Nonprofit Organizations. 1st Edn., Oxford University Press, New York, ISBN-10: 0199879702, pp: 360.

Pace, R., 2004. La Creazione di Valore Nelle Imprese Sociali. 1st Edn., Pitagora Editrice, Bologna, ISBN10: 8837115016 , pp: 300.

Perrini, F., Calcaterra M., Giorgieri A., 2002. Strumenti e servizi innovativi per la finanza etica: Il rating, in Economia e Management, n. 2.

Phalavani, M. and P. Ezzati, 2014. Are there smaller leverage effects in less-developed markets? Evidence from an oil exporting country. Am. J. Applied Sci., 7: 89-94. DOI: 10.3844/ajassp.2010.89.94

Poo-Inna, S., S.K. Jantakajon, T. Pantachai, 2014. Appropriate Model for Zoning Local Fish Conservation in front of Buddhist Temple on the Bank of the Chi River by Sustainable Community Participation. J. Soc. Sci., 5: 411-415. DOI: 10.3844/jssp.2009.411.415

Schena, C., 2003. Il problema del finanziamento del terzo settore in Italia, Università degli studi dell'Insumbria, Facoltà di Economia, Varese.

Teece, D.J. 1980. Economies of Scope and the Scope of The Enterprise. J. Econom. Behav. Organiz., 1: 223247. DOI: 10.1016/0167-2681(80)90002-5

Travaglini, C., 1997. Le cooperative sociali tra impresa e solidarietà. Clueb, Bologna.

Weisbrod, B., 1975. Private Good, Collective Good. The role of non profit sector. The Economics of Non Propertary Organization, Greenwich, Jai Press.

Zimmermann, H. 1999. Innovation in non-profit organizations. Annals of Public and Cooperative Economics. 